\title{
Filmes biodegradáveis à base de proteínas miofibrilares de pescado
} Biodegradable films based on myofibrillar proteins of fish

\section{Autores | Authors}

$\triangle$ Elessandra da Rosa ZAVAREZE

Universidade Federal do Pampa (UNIPAMPA) Pós-graduação em Engenharia e Ciência de Alimentos

Travessa 45, 1650, Malafaia Bagé/RS - Brasil e-mail: elessandrad@yahoo.com.br

Shanise Lisie Mello el HALAL Annie Campello TELLES Carlos PRENTICE-HERNÁNDEZ

Universidade Federal do Rio Grande (FURG)

Pós-graduação em Engenharia e Ciência de Alimentos Rio Grande/RS - Brasil e-mail: shanisemell@hotmail.com annie.ctelles@gmail.com dqmprent@furg.br

A Autor Correspondente / Corresponding Author Publicado / Published: dezembro/2012

\section{Resumo}

O objetivo deste trabalho foi estudar as propriedades físicas, mecânicas e de barreira dos filmes produzidos a partir de diferentes concentrações de proteínas miofibrilares de pescado de baixo valor comercial. O pescado utilizado foi a corvina (Micropogonias furnieri), que foi eviscerada e filetada. As proteínas miofibrilares foram obtidas do músculo, em sucessivas lavagens com água destilada. Os filmes foram produzidos com 3, 4 e 5\% de proteínas miofibrilares pelo método de casting. Os filmes foram analisados nos seguintes aspectos: espessura, solubilidade, opacidade, resistência à tração, elongação e permeabilidade ao vapor de água (PVA). O aumento da concentração de proteínas miofibrilares atribuiu aos filmes maior espessura, opacidade, resistência à tração e PVA; no entanto, conferiu menor elongação na ruptura dos mesmos.

Palavras-chave: Corvina; Solubilidade; Resistência à tração; Elongação.

\section{Abstract}

The objective of this work was to study the physical, mechanical and barrier properties of the films produced from different concentrations of myofibrillar proteins of fish. The fish used was croaker (Micropogonias furnieri), which was gutted and filleted. The myofibrillar proteins were obtained through the muscle with successive washes with distilled water. The films were made with 3, 4 and $5 \%$ of myofibrillar proteins by the method of casting. The films were analyzed by thickness, solubility, opacity, tensile strength, elongation and water vapor permeability (PVA). The increase of myofibrillar proteins concentration in the films increased thickness, opacity, tensile strength and water vapor permeability and reduced elongation at break of the film.

Key words: Croaker; Solubility; Tensile strength; Elongation. 


\section{Introdução}

O impacto ambiental a partir de resíduos de materiais plásticos não biodegradáveis constitui crescente preocupação global. Com a intenção de se substituir parcialmente esse tipo de material, vêm sendo realizadas pesquisas em busca de encontrar materiais poliméricos renováveis e ecológicos (KHWALDIA et al., 2010).

Filmes biodegradáveis são obtidos a partir de materiais biológicos; agem como barreira a elementos externos, pois podem proteger os produtos embalados de danos físicos e biológicos, assim como impedem a volatilização de compostos e a perda de umidade, aumentando a vida útil do produto. Entre os biopolímeros naturais mais utilizados, estão os polissacarídeos e as proteínas, os quais apresentam algumas vantagens, pois são provenientes de fontes renováveis e são capazes de formar uma matriz contínua e coesa (RHIM e NG, 2007). As proteínas possuem uma estrutura com 20 monômeros diferentes, o que confere uma ampla gama de propriedades funcionais, especialmente um potencial para ligações intermoleculares. Filmes à base de proteínas podem formar ligações em posições diferentes e oferecem grande potencial para a formação de numerosas ligações (OU et al., 2005). As proteínas de pescado apresentam algumas propriedades vantajosas na elaboração de filmes, como habilidade para formar redes, plasticidade e elasticidade, além de apresentar uma boa barreira ao oxigênio. No entanto, sua barreira ao vapor de água é baixa em razão da sua natureza hidrofílica, sendo que esta característica pode ser modificada pela adição de plastificantes e/ou aditivos.

De acordo com Dangaran et al. (2009), existem três tipos de proteínas de pescado: sarcoplasmática, estroma e miofibrilar. As enzimas, a mioglobina e as proteínas citoplasmáticas são exemplos de proteínas sarcoplasmáticas. Proteínas do estroma incluem colágeno e elastina, enquanto proteínas miofibrilares incluem miosina, actina, tropomiosina e troponina. Proteínas do estroma e miofibrilar são usadas para fazer filmes comestíveis e revestimentos. Actina e miosina formam as principais frações das proteínas miofibrilares. A miosina é responsável por uma série de propriedades, como a gelificação, a retenção de água e a emulsificação (RAGHAVAN e KRISTINSSON, 2008). As proteínas sarcoplasmáticas constituem cerca de $35 \%$ das proteínas totais do músculo e são solúveis em água independentemente da força iônica (OETTERER, 1996). As proteínas do estroma (tecido conectivo) - o colágeno e a elastina - são o resíduo da extração das proteínas sarcoplasmáticas e miofibrilares.

Proteínas de pescado, incluindo as proteínas miofibrilares e sarcoplasmáticas, têm sido utilizadas como material formador de filmes biodegradáveis por vários pesquisadores (IWATA et al., 2000; PASCHOALICK et al., 2003; SHIKU et al., 2003, 2004; ARTHARN et al., 2007). As proteínas miofibrilares são insolúveis em água, mas podem ser extraídas por meio da variação de $\mathrm{pH}$ da solução. Dentre as possíveis fontes de matéria proteica, está a corvina (Micropogonias furnieri), considerada, por sua abundância, uma das espécies mais importantes da pesca tradicional do Brasil, da Argentina e do Uruguai. Geralmente, é capturada ao longo de todo o ano, mas com maior intensidade nos meses de outubro a janeiro. Apesar de sua grande disponibilidade, atinge no mercado menores preços em relação a outras espécies. O objetivo deste trabalho foi estudar as propriedades físicas, mecânicas e de barreira dos filmes produzidos a partir de proteínas miofibrilares de pescado de baixo valor comercial.

\section{Material e métodos}

\subsection{Material}

Corvina (Micropogonias furnieri), capturada na região sul do Estado do Rio Grande do Sul, proveniente de uma indústria da cidade de Rio Grande-RS, Brasil. Os espécimes foram lavados em água clorada ( $5 \mathrm{ppm}$ ) a $4^{\circ} \mathrm{C}$ e logo submetidos às etapas de filetagem e evisceração. Os filés foram acondicionados em embalagens plásticas e armazenados em freezer a $-18^{\circ} \mathrm{C}$.

\subsection{Obtenção das proteínas miofibrilares}

Para obtenção das proteínas miofibrilares, foi utilizada a metodologia de Limpan et al. (2010). O músculo obtido a partir da corvina foi misturado com três volumes de água destilada fria e homogeneizado a $10.000 \mathrm{rpm}$ durante 2 minutos, seguido por filtração através de uma camada de tecido de nylon. A polpa homogeneizada foi misturada com 5 volumes de solução de $\mathrm{NaCl}(50 \mathrm{mM})$ por 5 minutos e foi filtrada novamente. O processo de lavagem foi repetido duas vezes e, após essa etapa, o material foi submetido à secagem em estufa de circulação forçada de ar a $40^{\circ} \mathrm{C}$.

\subsection{Preparação dos filmes}

Os filmes foram preparados de acordo com a metodologia de Limpan et al. (2010) com modificações. Os filmes com proteínas miofibrilares foram preparados por suspensão da proteína com 3,0, 4,0 e 5,0\% (p/v). O $\mathrm{pH}$ da solução foi ajustado para $11,0 \mathrm{com} \mathrm{NaOH} 1 \mathrm{M}$ e foi utilizado glicerol como plastificante $(0,30 \mathrm{~g}$ de glicerol. $\mathrm{g}$ de proteína. $\left.\mathrm{g}^{-1}\right)$. A solução foi homogeneizada com uma velocidade de $10.000 \mathrm{rpm}$ durante 5 minutos utilizando-se um homogeneizador Ultraturrax (IKA, T25 digital, Werke, Alemanha). A solução foi então agitada suavemente num agitador magnético durante 30 minutos a $90{ }^{\circ} \mathrm{C}$ para permitir a formação da película. As soluções filmogênicas foram espalhadas em placas de acrílico com $9 \mathrm{~cm}$ de 
diamêtro, sendo direcionadas para secagem em estufa com circulação de ar (modelo 520, Fanem, São Paulo, Brasil) a $40^{\circ} \mathrm{C}$ por 16 horas. Após a secagem, os filmes foram acondicionados a $25^{\circ} \mathrm{C}$.

\subsection{Espessura e solubilidade dos filmes}

A espessura dos filmes foi determinada por meio da média de oito medidas aleatórias em torno do filme, obdecendo a um afastamento da borda de $10 \mathrm{~mm}$, utilizando-se um micrômetro digital com resolução de 0,001 mm (Insize, IP54, São Paulo, Brasil).

Para determinação da solubilidade, os filmes foram recortados em discos de $2 \mathrm{~cm}$ de diâmetro e foi determinada a matéria seca inicial em estufa a $105^{\circ} \mathrm{C}$ por 24 horas. Após a primeira pesagem, as amostras foram imersas em recipientes contendo $50 \mathrm{~mL}$. O sistema foi agitado em Incubadora Shaker refrigerada (Cientec, CT-712RNT, São Paulo, Brasil) com velocidade de 150 rpm por um período de 24 horas, a $25^{\circ} \mathrm{C}$. Após este período, as amostras foram removidas e secas $\left(105^{\circ} \mathrm{C}\right.$ por 24 horas), para determinar a matéria seca que não se dissolveu em água (GONTARD et al., 1994).

\subsection{Opacidade dos filmes}

A opacidade dos filmes foi determinada utilizando-se Colorímetro (Minolta CR 400, Osaka, Japão), usando o sistema $\mathrm{CIEL}^{*} a^{*} b$. Para determinação da opacidade, foi calculada a relação entre a opacidade do filme sobreposto ao padrão preto $\left(P_{\text {preto }}\right)$ e ao padrão branco $\left(P_{\text {branco }}\right)$, segundo a Equação 1.

Opacidade $(\%)=\frac{\mathrm{P}_{\text {preto }}}{\mathrm{P}_{\text {branco }}} \times 100$

\subsection{Propriedades mecânicas dos filmes}

As propriedades mecânicas (resistência à tração e elongação na ruptura) dos filmes foram verificadas em texturômetro (modelo TA.TX, Stable Microsystems SMD, Reino Unido), empregando-se metodologia ASTM D882-91 (ASTM, 1996). As medidas foram conduzidas em temperatura ambiente $\left(25^{\circ} \mathrm{C}\right)$. A separação inicial das garras e a velocidade do probe foram de $50 \mathrm{~mm}$ e $1 \mathrm{~mm} . \mathrm{s}^{-1}$, respectivamente. As amostras foram cortadas em tiras de $100 \mathrm{~mm}$ de comprimento e $25 \mathrm{~mm}$ de largura. A resistência à tração (RT) e a porcentagem de elongação (E) foram calculadas pelas Equações 2 e 3, respectivamente.

$\mathrm{RT}=\frac{\mathrm{Fm}}{\mathrm{A}}$

em que: $R T$ : resistência à tração (MPa); Fm: força máxima no momento da ruptura do filme $(\mathrm{N})$; $A$ : área da secção transversal do filme $\left(\mathrm{m}^{2}\right)$.
$E(\%)=\frac{d r-d_{\text {inicial }}}{d_{\text {inicial }}} \times 100$

em que: $E$ : elongação (\%); dr: distância no momento da ruptura $(\mathrm{cm})$, que corresponde à diferença entre a distância de separação no momento da ruptura e a distância inicial $(5 \mathrm{~cm}) ; d_{\text {inicial }}$ : distância inicial de separação $(5 \mathrm{~cm})$.

\subsection{Permeabilidade ao vapor de água dos filmes}

A permeabilidade ao vapor de água (PVA) foi determinada utilizando-se o método ASTM E96-95 (ASTM, 1995). A amostra de filme foi selada na abertura circular de uma célula de permeação contendo cloreto de cálcio anidro (0\% de HR). Estas células de permeação foram colocadas em dessecadores com uma solução saturada de cloreto de sódio $(75 \% \mathrm{RH})$ e mantida a $25^{\circ} \mathrm{C}$. Após as amostras atingirem as condições de estado estacionário de peso, as células de permeação contendo o filme foram pesadas após 48 horas. A PVA foi calculada por meio da Equação 4.

$P V A=\frac{\Delta W}{t} \frac{X}{A \Delta P}$

em que: PVA: permeabilidade ao vapor de água (g.mm. $\mathrm{KPa}^{-1} \cdot$ dia $\left.^{-1} \cdot \mathrm{m}^{-2}\right) ; \Delta W$ : ganho de peso pelo dessecante (g); $X$ : espessura do filme (mm); t: tempo de incubação (dias); $A$ : área da superfície do filme exposto $\left(\mathrm{m}^{2}\right) ; \Delta P$ : diferença de pressão parcial (KPa).

\subsection{Análise estatística}

Os resultados foram submetidos à análise de variância e as médias comparadas pelo teste de Tukey no nível de 5\% de significância.

\section{Resultados e discussão}

\subsection{Espessura, solubilidade e opacidade dos filmes}

Os resultados de espessura, solubilidade e opacidade dos filmes biodegradáveis elaborados com diferentes concentrações de proteínas miofibrilares de pescado estão apresentados na Tabela 1. A espessura dos filmes foi controlada pelo volume de solução

Tabela 1. Espessura, solubilidade e opacidade de filmes à base de proteínas miofibrilares de pescado.

\begin{tabular}{cccc}
$\begin{array}{c}\text { Proteína } \\
\text { miofibrilar }(\%)\end{array}$ & $\begin{array}{c}\text { Espessura } \\
(\mathbf{m m})\end{array}$ & $\begin{array}{c}\text { Solubilidade } \\
(\%)\end{array}$ & $\begin{array}{c}\text { Opacidade } \\
(\%)\end{array}$ \\
\hline 3,0 & $0,137 \pm 0,006^{c}$ & $27,0 \pm 0,1^{a}$ & $12,0 \pm 0,3^{c}$ \\
4,0 & $0,173 \pm 0,012^{b}$ & $26,5 \pm 0,4^{a}$ & $12,7 \pm 0,2^{b}$ \\
5,0 & $0,223 \pm 0,006^{a}$ & $28,0 \pm 0,3^{a}$ & $13,5 \pm 0,2^{a}$ \\
\hline
\end{tabular}

Letras diferentes na mesma coluna diferem estatisticamente $(p<0,05)$. 
Tabela 2. Propriedades mecânicas e permeabilidade ao vapor de água de filmes à base de proteínas miofibrilares de pescado.

\begin{tabular}{|c|c|c|c|}
\hline $\begin{array}{c}\text { Proteína miofibrilar } \\
\qquad(\%)\end{array}$ & $\begin{array}{l}\text { Resistência à tração } \\
(\mathrm{MPa})\end{array}$ & $\begin{array}{c}\text { Elongação } \\
(\%)\end{array}$ & 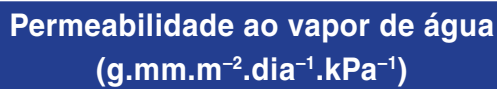 \\
\hline 3,0 & $4,09 \pm 0,15^{b}$ & $193,1 \pm 7,2^{\mathrm{a}}$ & $2,25 \pm 0,01^{b}$ \\
\hline 4,0 & $5,43 \pm 0,24^{a}$ & $173,2 \pm 6,8^{b}$ & $2,26 \pm 0,03^{b}$ \\
\hline 5,0 & $5,76 \pm 0,12^{a}$ & $102,6 \pm 5,4^{c}$ & $4,10 \pm 0,33^{a}$ \\
\hline
\end{tabular}

Letras diferentes na mesma coluna diferem estatisticamente $(p<0,05)$.

filmogênica colocada na placa de acrílico; no entanto, a concentração de proteína pode influenciar sua espessura.

A espessura dos filmes aumentou com o aumento da concentração de proteínas (Tabela 1). Uma ampla faixa de valores de espessura para filmes biodegradáveis tem sido reportada na literatura e, de acordo com García et al. (2009), a espessura do filme é dependente da sua composição e dos parâmetros de processamento do filme. A maior concentração de proteínas utilizada na formulação dos filmes induz ao aumento de sólidos na matriz polimérica formada após a secagem da solução filmogênica e, portanto, aumenta a espessura dos filmes biodegradáveis.

Todos os filmes apresentaram-se inteiros e intactos quanto à forma, bem flexíveis e dobráveis ao manuseio, após permanecerem imersos em água por 24 horas sob agitação. A solubilidade dos filmes depende dos componentes de sua estrutura. Proteínas com alta massa molecular são geralmente insolúveis ou pouco solúveis em água. Essas moléculas são interessantes, uma vez que podem formar filmes resistentes à água. Além disso, a solubilidade das proteínas depende muito do número e do arranjo de cargas na molécula, que dependerá da composição de aminoácidos (SGARBIERI, 1996). Os filmes apresentaram solubilidade em água entre $26,5 \%$ e 28,0\%; no entanto, o aumento na concentração de proteínas não alterou a solubilidade dos filmes (Tabela 1).

É importante que os filmes apresentem baixa opacidade, ou seja, maior transparência. A opacidade dos filmes elaborados com proteínas miofibrilares variou de $12,0 \%$ a $13,5 \%$ (Tabela 1 ), e houve um aumento na opacidade conforme se aumentou a concentração de proteínas miofibrilares de pescado na solução filmogênica. Estes valores foram superiores aos filmes produzidos com proteínas de músculo de tilápia-do-nilo (Oreochromis niloticus), que apresentou opacidade de 4,69\% (PASCHOALICK et al., 2003).

\subsection{Propriedades mecânicas e de barreira dos filmes}

Os resultados das propriedades mecânicas e da permeabilidade ao vapor de água dos filmes com diferentes concentrações de proteínas miofibrilares estão apresentados na Tabela 2.
Os filmes devem ter uma resistência mecânica suficiente para garantir a integridade dos mesmos quando utilizados como embalagem. Neste trabalho, a resistência à tração dos filmes aumentou à medida que a concentração de proteínas miofibrilares foi elevada (Tabela 2). De acordo com Perez-Gago e Krochta (2001), um aumento na concentração de proteínas fornece maior quantidade de grupos sulfidrílicos na superfície da proteína, promovendo maior número de pontes covalentes S-S na matriz do filme, formando, assim, filmes mais resistentes. García et al. (2005), que estudaram filmes com proteínas musculares de tilápia-do-nilo, também reportaram que o aumento da concentração de proteínas aumentou a resistência à tração dos filmes. O aumento do teor de proteínas reduziu a elongação na ruptura dos filmes (Tabela 2). A elongação na ruptura teve uma relação inversa com a espessura dos filmes (Tabela 1).

De acordo com Matta Junior et al. (2011), as propriedades de barreira dos filmes dependem da temperatura e da umidade relativa do ambiente, das características do biopolímero e da interação entre o polímero e o permeante, associada à polaridade. Dentre as características mais importantes do filme relacionadas à permeação, estão a espessura, a estrutura química do biopolímero e sua morfologia, a energia de coesão e o espaço livre entre as macromoléculas. Os filmes elaborados com maior concentração de proteínas (5\%) apresentaram maior permeabilidade ao vapor de água em comparação aos filmes com 3 e 4\% de proteínas (Tabela 2). Este aumento pode estar relacionado com a maior concentração de proteínas nos filmes, pois, segundo Di Pierro et al. (2006), a permeabilidade ao vapor de água dos filmes aumenta com quantidades crescentes de proteína, estando diretamente relacionada com o número de grupos polares (grupos laterais dos aminoácidos polares) disponíveis nas cadeias proteicas $(-\mathrm{OH},-\mathrm{COOH}$ e $-\mathrm{NH} 2)$.

\section{Conclusões}

O estudo mostrou que filmes elaborados com maior concentração de proteínas miofibrilares de pescado são mais espessos e opacos. Apresentam, ainda, maior resistência à tração e maior permeabilidade ao vapor de água; no entanto, são menos flexíveis. Portanto, é possível a elaboração de filmes a partir de proteínas miofibrilares originadas de pescados de baixo valor comercial; entretanto, são necessários mais estudos para 
Filmes biodegradáveis à base de proteínas miofibrilares de pescado

ZAVAREZE, E. R. et al.

melhorar o desempenho dos filmes, a fim de aumentar ainda mais sua resistência à tração e diminuir a sua taxa de permeabilidade ao vapor de água.

\section{Referências}

ARTHARN, A.; BENJAKUL, S.; PRODPRAN, T.; TANAKA, M. Properties of a protein-based film from round scad (Decapterus maruadsi) as affected by muscle types and washing. Food Chemistry, London, v. 103, n. 3, p. 867-874, 2007. http://dx.doi. org/10.1016/j.foodchem.2006.09.038

AMERICAN SOCIETY FOR TESTING AND MATERIALS - ASTM. Designation E96-95: Standard Method for Water Vapor Transmission of Materials. Philadelphia: ASTM, 1995. (Annual Book of ASTM Standards).

AMERICAN SOCIETY FOR TESTING AND MATERIALS - ASTM. D882-91: Standard Test Methods for Tensile Properties of Thin Plastic Sheeting. Philadelphia: ASTM, 1996. (Annual Book of ASTM Standards)

DANGARAN, K.; TOMASULA, P. M.; QI, P. Structure and function of protein-based edible films and coatings. In: EMBUSCADO, M. E.; KERRY C.; HUBER, K. C. (Eds.). Edible Films and Coatings for Food Applications. New York: Springer, 2009. p. 25-26. http://dx.doi.org/10.1007/978-0-387-92824-1_2

DI PIERRO, P.; CHICO, B.; VILLALONGA, R.; MARINIELLO, L.; DAMAIO, A. E.; MASI, P.; PORTA, R. Chitosan-Whey Protein Edible Films Produced in the Absence or Presence of Transglutaminase: Analysis of Their Mechanical and Barrier Properties. Biomacromolecules, Washington, v. 7, n. 3, p. 744-749, 2006. PMid:16529409. http://dx.doi.org/10.1021/ bm050661u

GARCÍA, F. T.; SOBRAL, P. J. A. Effect of the thermal treatment of the filmogenic solution on the mechanical properties, color and opacity of films based on muscle protein of two varieties of Tilapia. LWT- Food Science and Technology, v. 38, n. 3, p. 289-296, 2005. http://dx.doi.org/10.1016/j.Iwt.2004.06.002

GARCÍA, M. A.; PINOTTI, A.; MARTINO, M. N.; ZARITZKY, N. E. Characterization of starch and composite edible films and coatings. In: EMBUSCADO, M. E.; HUBER, K. C. (Eds.). Edible Films and Coatings for Food Applications. New York: Springer, 2009. p. 169-210. http://dx.doi.org/10.1007/978-0387-92824-1_6

GONTARD, N.; DUCHEZ, C.; CUQ, J.; GUILBERT, S. Edible composite films of wheat gluten and lipids: Water vapor permeability and other physical properties. International Journal Food Science Technology, Oxford, v. 29, n. 1, p. 39-50, 1994. http://dx.doi.org/10.1111/j.1365-2621.1994. tb02045.x

IWATA, K.; ISHIZAKI, S.; HANDA, A.; TANAKA, M. Preparation and characterization of edible films from fish water-soluble proteins. Fisheries Science, Tokyo, v. 66, n. 2, p. 372-378, 2000. http://dx.doi.org/10.1046/j.1444-2906.2000.00057.x
KHWALDIA, K.; ARAB-TEHRANY, E.; DESOBRY, S. Biopolymer coatings on paper packaging materials. Comprehensive Reviews in Food Science and Food Safety, Chicago, v. 9, n. 1, p. 82-91, 2010. http://dx.doi.org/10.1111/j.15414337.2009.00095.x

LIMPAN, N.; PRODPRAN, T.; BENJAKUL, S.; PRASARPRAN, S. Properties of biodegradable blend films based on fish myofibrillar protein and polyvinyl alcohol as influenced by blend composition and $\mathrm{pH}$ level. Journal Food Engineering, Essex, v. 100, n. 1, p. 85-92, 2010. http://dx.doi.org/10.1016/j.jfoodeng.2010.03.031

MATTA JUNIOR, M. D.; SARMENTO, S. B. S.; SARANTÓPOULOS, C. I. G. L.; ZOCCHI, S. S. Propriedades de Barreira e Solubilidade de Filmes de Amido de Ervilha Associado com Goma Xantana e Glicerol. Polímeros, São Carlos, v. 21, n. 1, p. 1- 6, 2011. http:// dx.doi.org/10.1590/S0104-14282011005000011

OetTeRER, M. Proteinas de Pescado. Piracicaba: ESALQ; USP, 1996.

OU, S.; WANG, Y.; TANG, S.; HUANG, C.; JACKSON, M. $G$. Role of ferulic acid in preparing edible films from soy protein isolate. Journal of Food Engineering, Essex, v. 70, n. 2, p. 205-210, 2005. http://dx.doi.org/10.1016/j. jfoodeng.2004.09.025

PASCHOALICK, T. M.; GARCIA, F. T.; SOBRAL, P. J. A.; HABITANTE, A. M. Q. B. Characterization of some functional properties of edible films based on muscle proteins of Nile tilapia. Food Hydrocolloids, Oxford, v. 17, n. 4, p. 419-427, 2003. http:// dx.doi.org/10.1016/S0268-005X(03)00031-6

PEREZ-GAGO, M. B.; KROCHTA, J. M. Denaturation time and temperature effects on solubility, tensile properties, and oxygen permeability of whey protein edible films. Journal of Food Science, Chicago, v. 66, n. 5, p. 705-710, 2001. http://dx.doi. org/10.1111/j.1365-2621.2001.tb04625.x

RAGHAVAN, S.; KRISTINSSON, H. G. Conformational and rheological changes in catfish myosin durinG alkaliinduced unfolding and refolding. Food Chemistry, London, v. 107, n. 1, p. 385-398, 2008. http://dx.doi.org/10.1016/j. foodchem.2007.08.037

RHIM, J. W.; NG, P. K. W. Natural biopolymer-based nanocomposite films for packaging applications. Critical Reviews in Food Science and Nutrition, Boca Raton, v. 47, n. 4, p. 411-433, 2007. PMid:17457725. http://dx.doi. org/10.1080/10408390600846366

SGARBIERI, V. C. Proteínas em Alimentos Protéicos: Propriedades, Degradações, Modificações. São Paulo: Editora-Livraria Varela, 1996. p. 139-157.

SHIKU, Y.; HAMAGUCHI, P. Y.; BENJAKUL, S.; VISESSANGUAN, W.; TANAKA, M. Effect of surimi quality on properties of edible films based on Alaska pollack. Food Chemistry, London, v. 86, n. 4, p. 493-499, 2004. http://dx.doi.org/10.1016/j. foodchem.2003.09.022

SHIKU, Y.; HAMAGUCHI, P.; TANAKA, M. Effect of $\mathrm{pH}$ on the preparation of edible films based on fish myofibrillar proteins. Fisheries Science, Tokyo, v. 69, n. 5, p. 1026-1032, 2003. http:// dx.doi.org/10.1046/j.1444-2906.2003.00722.x 